\title{
DENSITY-DEPENDENT SPILLOVER FROM A MARINE RESERVE: LONG-TERM EVIDENCE
}

\author{
Rene A. Abesamis ${ }^{1,2}$ And Garry R. Russ ${ }^{1,3}$ \\ ${ }^{1}$ School of Marine Biology and Aquaculture, James Cook University, Townsville, Queensland 4811 Australia \\ ${ }^{2}$ Silliman University Angelo King Center for Research and Environmental Management, Silliman University, \\ Dumaguete City 6200 Philippines
}

\begin{abstract}
Spillover, the net export of adult fish, is one mechanism by which no-take marine reserves may eventually have a positive influence on adjacent fisheries. Although evidence for spillover has increased recently, mechanisms inducing movement of adult fish from reserve to fished areas are poorly understood. While density-dependent export is a reasonable expectation, given that density of fish targeted by fisheries should increase over time inside well-protected no-take reserves, no study to date has demonstrated development of the process. This study provides evidence consistent with density-dependent export of a planktivorous reef fish, Naso vlamingii, from a small no-take reserve (protected for 20 years) at Apo Island, Philippines. Mean density of $N$. vlamingii increased threefold inside the reserve between 1983 and 2003. Density approached an asymptote inside the reserve after 15-20 years of protection. Modal size in the reserve increased from 35 to $45 \mathrm{~cm}$ total length (TL) over 20 years of protection. In addition, both density and modal size increased outside the reserve close to $(200-300 \mathrm{~m})$, but not farther from $(300-500 \mathrm{~m})$, the reserve boundary over the 20 years of reserve protection. Movement of adult $N$. vlamingii across the boundaries of the reserve was rare. Aggressive interactions among adult N. vlamingii were significantly higher (by 3.7 times) inside than outside the reserve. This suggests that density-dependent interactions were more intense inside the reserve. When interacting adults differed in size, the larger individual usually chased away the smaller one. Furthermore, the mean size of adult fish captured by experimental fishing decreased from 35 -cm TL 50$100 \mathrm{~m}$ outside the boundary, to 32-cm TL 250-300 m outside the boundary. This represents some of the best evidence available for density-dependent home-range relocation of fish from a no-take reserve.
\end{abstract}

Key words: Apo Island, Philippines; coral-reef fish; density dependence; fisheries management; fish movements; marine reserves; Naso vlamingii; spillover from no-take reserve.

\section{INTRODUCTION}

A large proportion of fish stocks are currently overexploited by marine capture fisheries (Jackson et al. 2001, NRC 2001, Pauly et al. 2002). No-take marine reserves are one potential solution to enhance the longterm sustainability of many of these fisheries (Dayton et al. 2000, NRC 2001, Gell and Roberts 2003, Sobel and Dahlgren 2004). A substantial amount of evidence indicates that the abundance and average size of organisms targeted by fisheries is increased inside notake marine reserves (Côté et al. 2001, NRC 2001, Gell and Roberts 2002, Halpern 2003, Sobel and Dahlgren 2004). However, to be useful as fisheries management tools, no-take marine reserves need to affect fished areas outside them in a positive manner (Russ 2002, Gell and Roberts 2003). Such effects include net export of adult and juvenile (post-settlement) targeted organisms ("spillover"), and net export of eggs and larvae of these organisms ("recruitment subsidy") (Russ

Manuscript received 31 January 2005; accepted 25 February 2005. Corresponding Editor: P. K. Dayton.

${ }^{3}$ Corresponding author; e-mail: garry.russ@jcu.edu.au
2002, Gell and Roberts 2003, Sobel and Dahlgren 2004, Sale et al. 2005). The use of marine reserves as fisheries management tools remains controversial, since clear demonstrations of such export functions are technically and logistically difficult (Russ 2002, Willis et al. 2003, Hilborn et al. 2004, Sale et al. 2005). For example, few studies have attempted to investigate spillover from notake marine reserves experimentally (Zeller et al. 2003).

Does spillover from no-take marine reserves occur, and if so, what mechanisms drive the process? To date, some of the best evidence for spillover comes from studies that have demonstrated increased abundance of targeted fish inside reserves and in adjacent fished areas over time (McClanahan and Kaunda-Arara 1996, Russ and Alcala 1996, McClanahan and Mangi 2000, Roberts et al. 2001, Russ et al. 2003, 2004, Kaunda-Arara and Rose 2004). However, none of these studies have provided evidence for mechanisms inducing movement of post-settlement fish from reserves to fished areas.

Mechanisms of spillover can be either density dependent or density independent (Russ 2002). Spillover is often assumed to be driven by density-dependent 
effects (Roberts and Polunin 1991, Sanchez Lizaso et al. 2000). Density-dependent movements may occur due to space limitation and territorial interactions. It implies a gradual development of a net export process driven by density-dependent interactions inside a reserve. This contrasts with export by simple diffusion from high density inside a reserve to low density outside. The latter process may occur simply because of random movements of fish across a reserve boundary. Simple diffusion can be considered density independent, at least in the sense that it requires no development of density-dependent behavioral mechanisms inside the reserve. Another mechanism of density-independent spillover of biomass involves movements of larger-than-average fish from reserve to fished areas in the course of normal daily and seasonal movements. Some density-independent export may also occur in the process of ontogenetic habitat shifts.

The term "density dependence" is most often applied to questions of population regulation (Hixon and Webster 2002, Sutherland et al. 2002). Density dependence occurs when input to a population (births, immigration) varies negatively with population size, and losses (deaths, emigration) vary positively with population size (Hixon and Webster 2002). At the spatial scale of an entire reproductively closed marine population, the metapopulation (a group of local populations linked by larval dispersal), the processes of immigration and emigration are, by definition, not relevant (Hixon and Webster 2002). Such metapopulations are made up of local populations. These are groups of conspecifics that spawn only with other group members. The groups are also sufficiently isolated from other such groups that movement of adults between them is demographically negligible (Hixon and Webster 2002).

Most no-take marine reserves, or the no-take components of marine-reserve networks, established to date are small (median of $4 \mathrm{~km}^{2}$ for $n=70$ no-take reserves, Halpern 2003). Reserves of this size are often at, or less than, the spatial scale of local populations of exploited marine organisms. Under such circumstances the processes of emigration and immigration are relevant to the sizes of components of local populations and subpopulations inside no-take reserves. Whether movements are density dependent or density independent within reserves has important theoretical predictions and practical considerations. Density-dependent emigration predicts higher rates of aggressive interactions between conspecifics in no-take reserves, where density and average size of targeted fish are higher. These higher rates of aggressive interactions are predicted to induce subordinate fish to relocate their home range to outside the reserve, rather than to stay in the reserve (Kramer and Chapman 1999). Clearly this will depend on the availability of suitable habitat for the fish outside the reserve. If the density-dependent aggressive interactions are such that larger fish dominate smaller fish (Robertson 1998), one may predict that, for a reserve well protected in the long term, a gradient of mean size may occur from inside to outside the reserve (Rakitin and Kramer 1996, Kramer and Chapman 1999). Such predictions do not apply, or are less likely, in the case of density-independent spillover. Note, however that decreasing gradients of either biomass or catch rate as one moves from reserve to fished areas may develop from spillover driven by either mechanism. That is, even a simple diffusion process from high to low density may result in higher density just outside the reserve, relative to further away, if the fishery does not immediately harvest any fish that have spilled over.

Density-dependent movement occurs when the rate and directionality of individual movements change with population density (Sutherland et al. 2002). Competition, including behavioral interactions that involve territoriality and dominance hierarchies, and predation are the major processes by which density dependence can influence movement patterns of animals (Sutherland et al. 2002). Some insects, birds, and small terrestrial vertebrates move in response to changes in density (Sutherland et al. 2002). However, the role of density-dependent processes in determining movement of coral-reef fishes is largely unknown (Jones and McCormick 2002). In recent reviews of density-dependent processes in reef-fish populations (Armsworth 2002, Hixon and Webster 2002) the potential effects of density dependence on movement of reef fish was not discussed. Rose et al. (2001), in a review of compensatory density dependence in fish populations, concluded that density-dependent movement of fishes affecting mortality and reproductive success was well documented in fishes. However, almost all of the empirical evidence cited to support this conclusion involved studies of salmonids in rivers and streams.

Competition for resources (usually food, shelter, or breeding partners) in coral-reef fishes is often manifested in aggressive interactions (interference competition) among individuals (Shulman 1985, Robertson and Gaines 1986, Mumby and Wabnitz 2002, Morgan and Kramer 2005). A higher frequency of aggressive interactions inside compared to outside a no-take reserve may develop over time if increased population density results in greater competition for resources inside a reserve. Morgan and Kramer (2005) recently have shown that the incidence of territoriality in a $\mathrm{Ca}$ ribbean surgeonfish, Acanthurus coeruleus, increased with increasing population density. Surprisingly, no studies have examined how the intensity of competitive interactions differs inside and outside no-take reserves. Also, few studies have verified the predicted pattern of decreasing mean size of fish from inside to outside a reserve (Rakitin and Kramer 1996, Kramer and Chapman 1999).

However, home-range relocation is considered rare in reef fishes because many species display strong site attachment (Sale 1978). Fishes of smaller body size, 


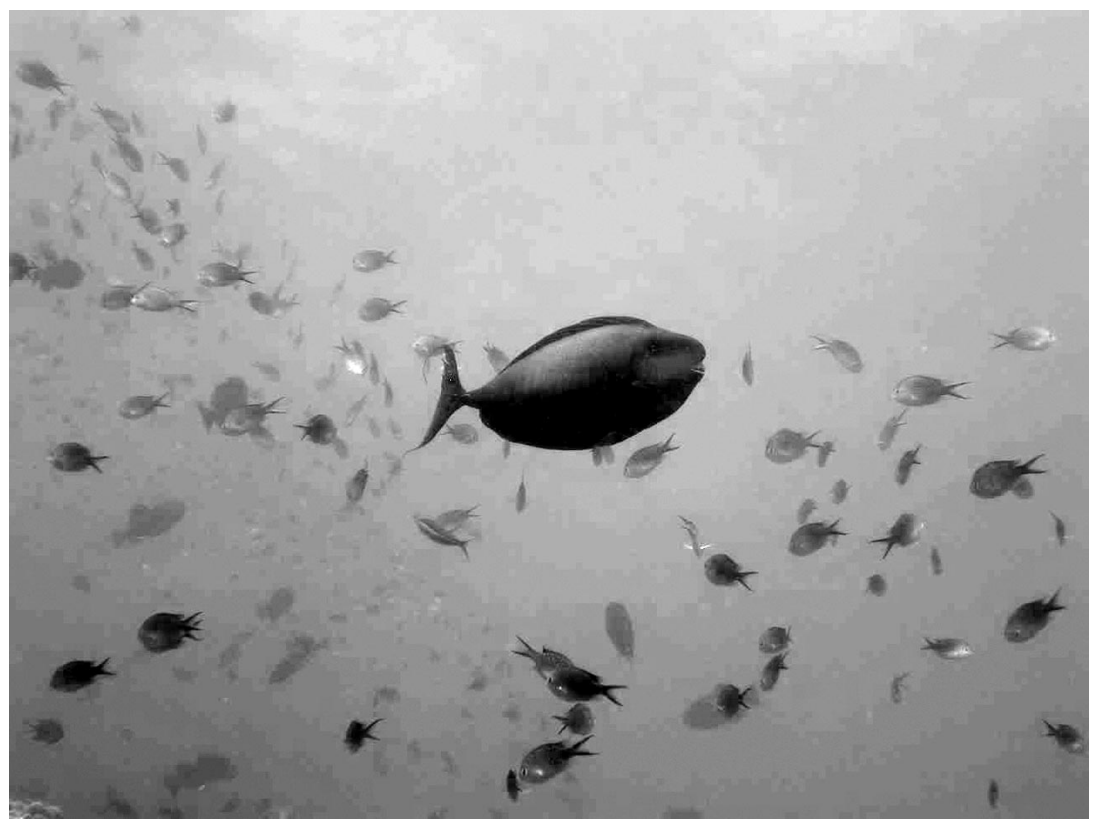

Plate 1. The surgeonfish Naso vlamingii feeding on plankton on the coral reef slope of Apo Island No-take Marine Reserve in the Philippines. Photo credit: R. Abesamis.

in particular, may be reluctant to relocate because of a higher cost of growth and/or risk of mortality associated with relocation (Kramer and Chapman 1999). Nonetheless, evidence for home-range relocation in reef fishes is increasing (Robertson 1988, Lewis 1997). Furthermore, larger or more mobile reef fishes may display movement that is significant at spatial scales presumed to be relevant to spillover from reserves (tens of meters to a few kilometers). Some reef fishes, for instance, may migrate across different habitats, reef zones, or along a depth gradient during ontogeny (Cocheret de la Moriniere et al. 2002, Meyer et al. 2000, Nagelkerken and van der Velde 2002). Ontogenetic movement may indicate behavioral decisions that aim to maximize net benefits by increasing growth rate and lowering risk of mortality (Dahlgren and Eggleston 2000). Some behavioral decisions leading to shifts in habitat may be influenced by density-dependent factors.

Does the mechanism of spillover matter? Clearly, density-dependent spillover will only begin to operate when density of the target species in the no-take reserve is high enough to induce home-range relocation of subordinate fish, driven out by high rates of aggressive interactions in the reserve. In other words, the reserve should be close to reaching the carrying capacity of the local environment ("filling up"). Under such circumstances, one would not expect to detect spillover for a long time after reserve establishment, depending on the recovery rate of the species and the local environmental conditions. Recovery rates of populations in no-take reserves will depend on many factors, such as initial population size, intrinsic rate of population growth, success of recruitment, flux rates across reserve boundaries, and the degree of reduction of fishing mortality inside the reserve (Jennings 2001). Russ (2002) and Russ and Alcala (2004) have suggested that development of spillover through density-dependent emigration of adult fish may take years to decades to develop.

It is often assumed also that spillover may occur through the occasional density-independent emigration of some fish from a reserve (Roberts and Polunin 1991, Gell and Roberts 2002, Russ 2002). Fish may emigrate from a reserve during daily or seasonal movements within their home ranges (Holland et al. 1996, Zeller and Russ 1998, Meyer et al. 2000, Eristhee and Oxenford 2001, Tremain et al. 2004). Also, larger fish may have higher potential for emigration because they have larger home ranges (Kramer and Chapman 1999).

Higher emigration rates of individuals across reserve boundaries, due to either density-dependent or densityindependent processes, may slow down the recovery rate of populations in reserves (Jennings 2001). Recovery of populations in reserves, and subsequent spillover, would require that some individuals residing in a reserve usually remain within the reserve (Willis et al. 2001). Reserves that are established for the benefit of local fisheries must somehow be large enough to promote population recovery, yet small enough to permit some spillover.

Density-dependent spillover also implies that populations may have recovered more completely compared to those demonstrating density-independent spillover. The latter process implies a simple diffusiontype equilibration as soon as density is higher inside 
than outside the reserve, which may be expressed more quickly, not requiring a complete recovery. These differences between density-dependent and density-independent spillover suggest that populations are functioning differently inside than outside reserves in the former, but not the latter case.

Our present study provides evidence consistent with one mechanism for the spillover of an exploited planktivorous surgeonfish, Naso vlamingii, from a small notake reserve at Apo Island, in the Philippines (see Plate 1). It builds on a previous study, which documented an increase in the biomass of $N$. vlamingii in this reserve and an adjacent fished area, over almost two decades (Russ et al. 2003). This previous study also found higher hook-and-line catch rates of $N$. vlamingii closer to than further away from the boundaries of the reserve (Russ et al. 2003). In the present study, the short-term movement of $N$. vlamingii across the reserve boundary was assessed directly by visual tracking of individuals. The spatial pattern of catch per unit effort and mean size of $N$. vlamingii caught outside the reserve was determined by experimental hook-and-line fishing. Lastly, we investigated the frequencies of aggressive interactions among different size classes of $N$. vlamingii to determine whether density-dependent interactions were more frequent inside than outside the reserve, and if a size-related dominance hierarchy existed. This information, combined with data on the change in density and size structure of $N$. vlamingii inside the reserve and at different distances from the reserve boundary over a 20-year period, are used to address the question: Is density-dependent spillover of Naso vlamingii from the Apo no-take reserve likely?

\section{Methods}

\section{Study species}

Naso vlamingii is one of several larger species of surgeonfish (Acanthuridae) that are exploited by the local fishery at Apo Island. The species prefers seaward reef slopes, from 4 to $50 \mathrm{~m}$ deep (Lieske and Myers 1997). It can grow to $50 \mathrm{~cm}$ total length (TL) (Lieske and Myers 1997), and may live up to 45 years (Choat and Axe 1996). Adult N. vlamingii feed on zooplankton during the day (Lieske and Myers 1997). They are usually found solitary or in pairs, but may form aggregations off steep reef slopes and drop-offs when feeding. Larger individuals (presumably males) have the ability to display their blue body markings during interactions with conspecifics or other species. Such a display may be related to territorial or mating behavior (Lieske and Myers 1997), but little else is known about the behavior and social organization of the species.

\section{Study site}

Apo Island $\left(9^{\circ} 4^{\prime} \mathrm{N}, 123^{\circ} 17^{\prime} \mathrm{E}\right)$ is located in the central Philippines, southeast of Negros Island (Fig. 1). It is a small volcanic island inhabited by a community



FIG. 1. Map of Apo Island, central Philippines, showing the no-take reserve (shaded). Black rectangles in the reserve and the fished non-reserve area (on the southwestern side of Apo Island) show the approximate positions of individual 50 $\times 20 \mathrm{~m}$ transects where underwater visual censuses were made from 1983 through 2003. Open circles indicate the approximate positions of eight sites outside the reserve that were fished for Naso vlamingii using traditional hook-and-line fishing. The distances of these fished sites from the northern $(\mathrm{N})$ or southern (S) boundary are also shown. The white, curving rectangle enclosed by dots shows the approximate area where visual observations of the movement and behavior of individual $N$. vlamingii were made.

of about 700 residents. The island has a coral-reef area of about $0.54 \mathrm{~km}^{2}$ (to the $20 \mathrm{~m}$ isobath). Reef fisheries and tourism are the main sources of income for the community (Russ and Alcala 1999). A 450-m-long no-take reserve on the southeastern side of Apo Island (Fig. 1) was established in 1982 (Russ and Alcala 1999). Protection of the reserve from fishing is strictly enforced by the community, with good compliance from local people and visitors (Russ and Alcala 1999). Outside the reserve, fishers from Apo Island and from nearby towns on Negros Island engage in artisanal and subsistence fishing methods nondestructive to coral habitats. The coral-reef slope in the reserve and in fished areas close to the lateral boundaries of the reserve is relatively steep and rugose, with high hardcoral cover. Apo Island is influenced by a strong mainstream current from the north (Fig. 1). This makes the northern side of the island favorable for fishing, targeting mostly Carangidae (jacks) during the southwestern monsoon (June to September) and in the interim calm periods (April, May, and October) (Bellwood 1988). However, during the northeastern monsoon (November to March) locals tend to fish the southern and western sides of the island. Local people 
consider the southern end of Apo Island as a traditional fishing ground for Naso vlamingii (called "bongko$k a n "$ in the local dialect), referring to this area as " $T u$ moy" or "Rock Point" (M. Pascobello, Apo Island resident/Barangay Chairman, personal communication) (Fig. 1). Fishers at Apo Island catch N. vlamingii using large bamboo traps, spears, and hook and line.

\section{Visual census in the reserve and non-reserve}

Estimates of density and size structure were made at the reserve and a non-reserve (fished) site (Fig. 1) in December or November of each year, 1983-2003, except for the years 1984, 1986-1987, 1996, and 2002. The method of "underwater visual census" (UVC) has been published elsewhere (Russ and Alcala 1996). Six $1000-\mathrm{m}^{2}(50 \times 20 \mathrm{~m})$ replicate areas of reef slope were censused in the reserve (2-17 $\mathrm{m}$ depth) and at the fished non-reserve site $(9-17 \mathrm{~m})$ on each sampling occasion. The observer (G. R. Russ), the method of UVC, and the position of the replicates were the same from 1983 through 2003 (except that some replicate areas at the non-reserve site differed between 1983 and all other times). The $50 \times 20 \mathrm{~m}$ replicate areas were spread evenly along the northern section of the reserve. The replicate areas were placed within $\sim 10 \mathrm{~m}$ of each other to ensure that six replicates would sample most $(>80 \%)$ of the reserve. The non-reserve (fished control) site at Katipanan fishing ground (Fig. 1) was originally chosen as it was the closest site to the reserve that had a benthic habitat as similar as possible to the reserve, and offered all-weather access to diving. The $50 \times 20 \mathrm{~m}$ replicate areas were spaced in the same arrangement as those in the reserve (Fig. 1). Counts and estimates of total length $( \pm 5 \mathrm{~cm})$ of Naso vlamingii were made. Juveniles $(<10 \mathrm{~cm}$ TL) were not counted. Spatial distribution of fish density over time at the non-reserve site was estimated using the methods described in Russ and Alcala (1996). Estimates of density were made for adjacent pairs of $50 \times 20 \mathrm{~m}$ replicate plots in the non-reserve area at distances of $200-300 \mathrm{~m}, 300-400 \mathrm{~m}$, and 400$500 \mathrm{~m}$ from the southern boundary of the reserve (Fig. $1)$. These density estimates were averaged for the four periods 1983-1987 (early phase of reserve protection), 1988-1992, 1993-1997, and 1998-2003 (mid- to late phase of reserve protection).

Line-intercept transect (LIT) estimates of benthic cover were made at most sampling times at Apo reserve (except 1988-1992) and Apo non-reserve (except 1985-1992). Nine (reserve) and six (non-reserve) replicate 20-m LITs were taken on the reef slopes (4-7 m depth at Apo reserve, 9-12 $\mathrm{m}$ at Apo non-reserve) in the same areas where the UVC for fish were made. The only exception to the use of the LIT method for estimating benthic cover was during 1999-2003. In these years, each of the six $50 \times 20 \mathrm{~m}$ plots used to survey fish at each reserve and non-reserve site were divided into ten $10 \times 10 \mathrm{~m}$ quadrats. The percent cover of all benthic substrata, including hard corals, was estimated by eye (in units of 5\%) for each quadrat. The diver also scored the rugosity of the reef substratum [0 (least rugose) to 4 (most rugose)] and the steepness of the reef slope [0 (horizontal) to 4 (vertical)] visually for every quadrat. The average of the 10 quadrats was taken as the percent cover of each benthic category, rugosity, and slope over the entire replicate plot.

Detailed estimates of rugosity and steepness of slope were not made until 1999. Steepness of slope was constant over the study period (1983-2003) at both sites. To estimate rugosity before 1999 , we used the detailed data collected in 1999-2001 at Apo and nearby Sumilon Island (Russ et al. 2005) to calculate a predictive relationship between the percent cover of sand + rubble + bare substratum and the rugosity index. This relationship was highly significant (rugosity $=-0.02 \times$ (percent cover sand + rubble + bare substratum) + $\left.3.53 ; r^{2}=0.28, F_{1,234}=90.26, P<0.001\right)$. A correction factor had to be applied to this predictive relationship to prevent underestimation of rugosity at Apo reserve (by 0.16 ) and overestimation of rugosity at Apo nonreserve (by 0.61). This predictive relationship, with its site-specific correction factor, was used to predict rugosity for sample times before 1999 .

Description of the benthic habitat for each site and time was estimated as a single habitat-complexity index (HCI) (R. A. Abesamis, G. R. Russ, and A. C. Alcala, unpublished manuscript): $\mathrm{HCI}=$ (proportion of live hard coral cover +1$) \times($ mean rugosity +1$) \times($ mean reef steepness +1$)$. This index ranges from 1 through 50. Higher values indicate steeper reef faces with high hard-coral cover and rugosity. Lower values indicate relatively flat expanses of sand, rubble, or rock, with low hard-coral cover.

The effects of reserve status and time on the density of $N$. vlamingii were analyzed by a repeated-measures analysis of variance (ANOVA), since the same six replicate areas were censused at the reserve and non-reserve sites at each sampling time. In addition, to account for any effects of habitat differences between the reserve and non-reserve sites, and any changes in habitat at these sites over time, a repeated-measures analysis of covariance (ANCOVA) was performed, with density of N. vlamingii the variate, and HCI the covariate. This analysis was performed for those times where a HCI estimate was available (all years but 1985-1992). Density and HCI data were $\log (x+1)$ transformed to satisfy assumptions of these analyses.

The temporal trends in density of $N$. vlamingii in the reserve and non-reserve were further examined by linear regression. A visual inspection of the density of $N$. vlamingii against years of reserve protection in Apo reserve suggested evidence of an asymptotic relationship. We used nonlinear estimation to find the bestfitting logistic growth model for these data. The model is $D_{\mathrm{t}}=K\left(1+e^{-r(t+\mathrm{t} 0)}\right)^{-1}$, where $D_{t}$ is density (number/ $\left.1000 \mathrm{~m}^{2}\right), K=$ carrying capacity, $r$ is the intrinsic rate of natural increase, $t$ is duration of protection, $t_{0}$ is the 
theoretical time at which density is zero, and $e$ is the base of natural logarithms (Kaufman 1981). The parameters to be estimated in this model are $K, r$, and $t_{0}$.

The significance of changes in the spatial distribution of density of $N$. vlamingii over time at the non-reserve site was tested by chi-square tests. Size frequency distributions of $N$. vlamingii were compared among four time periods (1983-1987, 1988-1992, 1993-1997, and 1998-2003) by Kolmogorov-Smirnov tests in the reserve and at two distances from the reserve boundary (200-300 m, 300-500 m).

\section{Experimental fishing adjacent to the reserve}

Two experienced local fishers conducted traditional hook-and-line fishing in the two fished areas adjacent to the lateral (northern and southern) boundaries of Apo reserve and in two fishing areas far from $(400 \mathrm{~m}$ and $500 \mathrm{~m}$ ) the reserve (Fig. 1). The hook-and-line technique they used specifically targeted Naso vlamingii (but other planktivorous and some omnivorous fishes were also caught). This technique involves using a very small hook attached to a fine line made of nylon and twine. The hook is baited with a small piece of fish skin or intestine (usually from Decapterus spp.). Using the twine portion of the line, the hook is wrapped around a small stone together with finely minced fish chum. The line is secured around the stone using a type of slipknot. At the desired depth, the stone is released to scatter the chum and free the hook. Planktivorous fish are attracted to the scattered chum and usually reach the baited hook first. Hook-and-line fishing for $N$. vlamingii was done above the reef slope (between 10 and $20 \mathrm{~m}$ deep) in the two fished areas, at three distances from the reserve boundary: 50-100 m, 150$200 \mathrm{~m}$, and 250-300 m (Fig. 1). Marker buoys were installed at each distance from the reserve with the aid of a GPS. Each distance was fished during both the flood and ebb tides. Eight replicates of $1 \mathrm{~h}$ of fishing were made at each distance for each tide (96 hours of experimental fishing). Experimental fishing was done from 20 September to 3 October 2003, between 07:00 and 17:00 hours. Fishing among sites was random (weather permitting). In addition, the same technique of experimental fishing was used to sample two sites $400 \mathrm{~m}$ and $500 \mathrm{~m}$ from the southern boundary of the reserve (the southwestern side of the island-see Fig.1) in December 2003. Each site was fished for four replicate 1-h sessions at each of two tides (ebb, flood), a total of $16 \mathrm{~h}$ of sampling for the sites 400 and $500 \mathrm{~m}$ from the reserve boundary. Thus, a total of $112 \mathrm{~h}$ of experimental fishing for $N$. vlaminggi was carried out at five different distances from reserve boundaries over the entire study. All N. vlamingii caught were weighed using a market scale accurate to $0.01 \mathrm{~kg}$ and their lengths (centimeters TL) measured. Catch rates of $N$. vlamingii were expressed in fish per person per hour. A three-way ANOVA was used to examine how catch rates of $N$. vlamingii varied among the two fished areas adjacent to the reserve (northern, southern), three distances from the reserve boundaries $(50-100 \mathrm{~m}, 150-$ $200 \mathrm{~m}$, and 250-300 m) and two tides (ebb, flood). Multiple comparisons of mean catch rates at each of the three distances were made using Tukey's test. A two-way ANOVA was used to examine how mean size of $N$. vlamingii varied among the fished areas (northern, southern) adjacent to the reserve and among three distances from the reserve boundaries.

\section{Observations of movement and aggressive interactions}

One person on snorkel (R. A. Abesamis) observed the movement and behavior of individual Naso vlamingii in the reserve and in the fished area adjacent to the northern boundary of the reserve. Observations were not made in the fished area directly adjacent to the southern boundary of the reserve for safety reasons (currents in this area are unpredictable and usually strong). Observations were made on the reef slope, in an area $\sim 600 \mathrm{~m}$ long between the 5- and 12-m isobaths (Fig. 1). This area was divided equally into six sectors, three sectors each in the reserve and in the fished area. Four observations of individuals were allotted to each of three size classes ( $\leq 30,31-40$, and $\geq 41 \mathrm{~cm} \mathrm{TL})$ in each sector. Sampling was made randomly among sectors and among size classes, but neighboring sectors were sampled at the same time of day (morning, noon, or afternoon) in order to decrease the time required to swim among sectors. However, sampling moved on if no individual of a given size class was seen for at least 15 minutes within a sector.

At the beginning of each observation period, the observer estimated the length (centimeters TL) of the individual and noted its starting position. The observer made use of a conspicuous natural underwater feature to identify the starting position. The observer also estimated the distance of the starting position from the northern boundary of the reserve using landmarks on shore. The maximum distance moved laterally by the individual towards the northern or southern reserve boundary, in increments of $10 \mathrm{~m}$, was recorded every minute. Behavioral interactions with conspecifics were also recorded every minute. The behaviors observed were: aggression towards smaller conspecifics, aggression towards larger conspecifics, aggression towards similarly sized conspecifics, fleeing from a smaller conspecific, fleeing from a larger conspecific, and fleeing from a similarly sized conspecific. Other behaviors (e.g., feeding) and aggressive interactions with other species were also recorded. Individuals were considered to show aggressive behavior when they chased another individual away. Larger individuals also show aggressive behavior by displaying blue body markings to another individual. However, larger individuals may also display their blue markings without also showing aggressive behavior, such as when visiting a cleaning station. Individuals were observed for a maximum of 
15 min or until they were lost from view (observation time for each individual in reserve: range, 3-15 min; mode $=15 \mathrm{~min}$; fished area: range, 3-15 min; mode, $10 \mathrm{~min}$ ). Only individuals that were observed for a minimum of 4 min were included in the analyses of movement and behavior. For each individual, the frequency of an observed behavior was estimated as the number of times the behavior was observed, divided by total observation time (in minutes). The observer always kept a reasonable distance $(\sim 5 \mathrm{~m})$ from the fish to avoid influencing its natural behavior. These observations (a total of $35 \mathrm{~h}$ ) were made from 5 to $8 \mathrm{De}$ cember 2003, between 07:00 and 16:00 hours.

The methodology described above was designed initially to measure short-term movements of individual fish. Despite the substantial observation period on snorkel $(35 \mathrm{~h})$, the total number of observed aggressive interactions between $N$. vlamingii individuals was insufficient to detect a statistically significant difference in rates of such interactions between reserve and nonreserve sites. A major limitation of the sampling on snorkel was that $N$. vlamingii density and average size generally increased with depth. Thus interaction rates of fish were greater at depths that were difficult to sample on snorkel. A new sampling technique, designed to record all aggressive interactions in a given replicate area $(25 \times 10 \mathrm{~m})$ in a given time $(15 \mathrm{~min})$ was used in November, 2004. We sampled the entire reserve area ( $n=18$ replicates) and the non-reserve area $(n=22$ replicates, spread approximately evenly outside the northern and southern reserve boundaries). In each replicate one of two experienced observers used scuba and swam slowly along a 25-m-long tape, laid at $10-15 \mathrm{~m}$ depth on the reef slope. The observer recorded all aggressive interactions between individual $N$. vlamingii within $5 \mathrm{~m}$ of either side of the tape, during a 15-min swim. The relative sizes of interacting fish were recorded to $\pm 5 \mathrm{~cm}$. In addition, notes were made on the likely reason for any aggressive interactions (competition for feeding sites, mates) and if the interaction resulted in one fish chasing the other from the area. The rates of aggressive interactions inside and outside the reserve were compared with a $t$ test. Data were transformed $(\log (x+1))$ to satisfy assumptions of equal variance of samples.

\section{RESUlts}

\section{Changes in density and size structure in the reserve and non-reserve}

A repeated-measures ANOVA indicated significant effects of reserve $\left(F_{1,10}=59.72, P<0.001\right)$ and time $\left(F_{14,140}=3.14, P<0.01\right)$ on density of Naso vlamingii. The reserve $\times$ time interaction was, however, not significant $\left(F_{14,140}=1.21, P>0.05\right)$ for this analysis. The density of $N$. vlamingii tripled inside the reserve over 20 years of protection from fishing from $6.2 \pm 0.87$ to $18.2 \pm 1.96($ mean $\pm \mathrm{SE})$ fish/1000 $\mathrm{m}^{2}$ between 1983



FIG. 2. Density of Naso vlamingii, inside and outside the marine reserve. (a) Mean density of $N$. vlamingii in the notake reserve (solid circles) and a fished non-reserve site (open circles) at Apo Island from 1983 to 2003, corresponding to 1-21 years of protection in the reserve. The regression line was significant for the reserve (mean density $=0.45 \times[$ Years of Protection] + 8.36; $\left.r^{2}=0.54, F_{1.13}=15.51, P<0.01\right)$, but not for the non-reserve. (b) Logistic growth curve fitted to the data on mean density of $N$. vlamingii inside Apo reserve. The curve suggests an inflection between 6 and 9 years of protection, and approaches an asymptote of $15.88 \mathrm{fish} /$ $1000 \mathrm{~m}^{2}$ after $15-20$ years of protection. (c) Density of $N$. vlamingii at the non-reserve site at different distances from the reserve boundary in four different time periods: 19831987, 1988-1992, 1993-1997, and 1998-2003. Error bars indicate SE. See Fig. 1 for the position of transects in the non-reserve site on the southwestern side of the island.

and 2003 (Fig. 2a). There was a significant positive relationship between duration of reserve protection and density of $N$. vlamingii inside (Fig. 2a, mean density $=0.45 \times$ [Years of Protection] $+8.36 ; r^{2}=0.54, F_{1,13}$ $=15.51, P<0.01$ ) but not outside the reserve (Fig. $2 \mathrm{a}$, mean density $=0.12 \times[$ Years Fished $]+1.97 ; r^{2}$ 


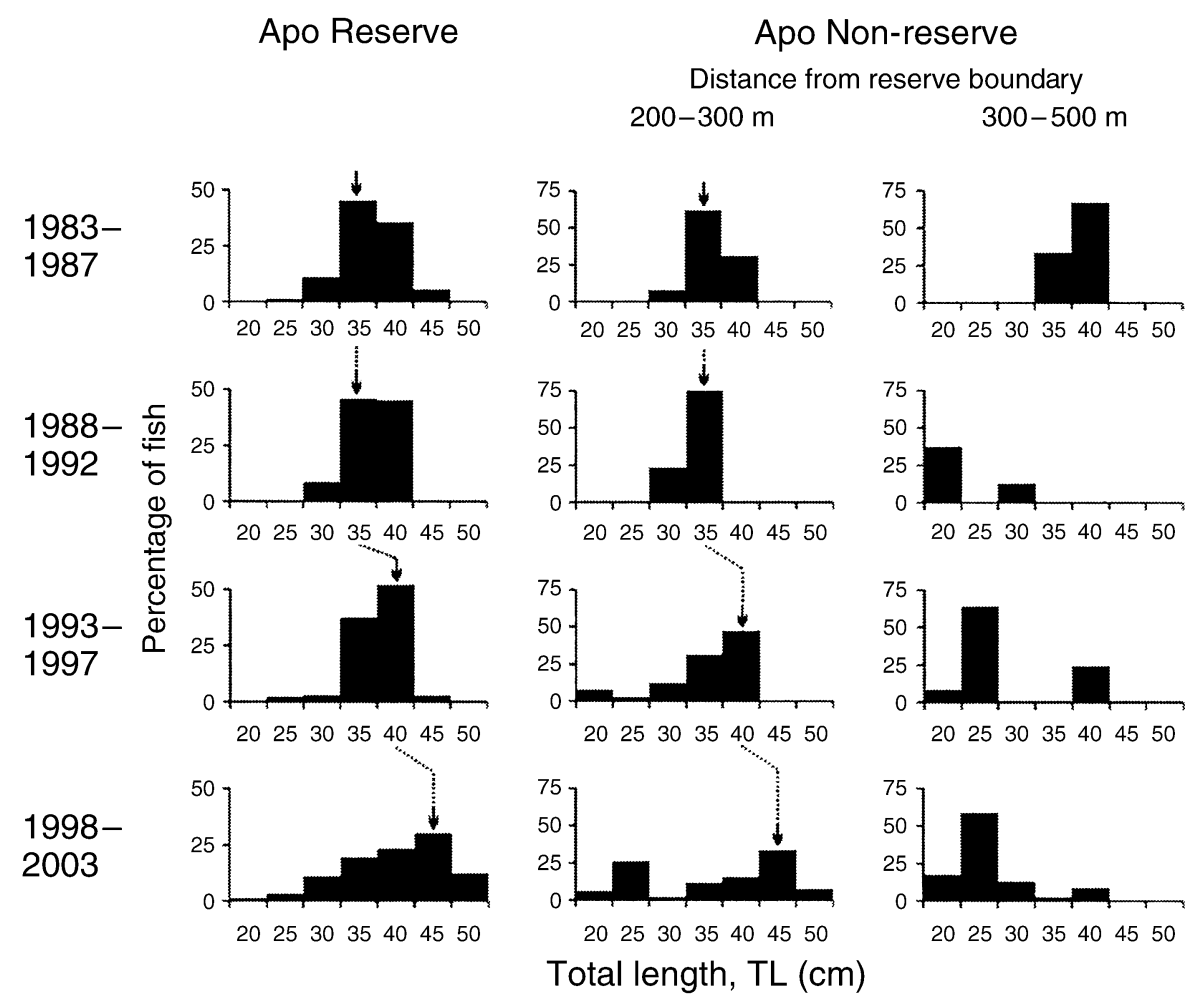

FIG. 3. Size frequency distribution of Naso vlamingii at Apo Island in the no-take reserve and in a fished non-reserve site from 1983-1987 to 1998-2003. The size frequency distribution in the non-reserve site is shown for two distance categories from the reserve boundary: 200-300 m (near) and 300-500 m (far). Arrows trace changes in modal size through time. See Fig. 1 for the position of transects in the non-reserve site on the southwestern side of the island.

$\left.=0.07, F_{1,13}=0.95, P>0.05\right)$. The slope of the relationship between density and duration of reserve protection inside the reserve was 3.8 times greater than that for the non-reserve, with the slopes in Fig. 2 a close to being significantly different $\left(t_{26}=1.99,0.1<P>\right.$ 0.05).

A repeated-measures ANCOVA, using a habitat complexity index $(\mathrm{HCI})$ as the covariate, indicated a nonsignificant effect of reserve $\left(F_{1,9}=0.38, P>0.05\right)$ but a significant effect of time $\left(F_{9,81}=4.36, P<0.001\right)$ on density of Naso vlamingii. The reserve $\times$ time interaction for this analysis was significant $\left(F_{9,81}=9.92\right.$, $P<0.001)$. This indicates that when the effects of habitat between the reserve and non-reserve sites, and changes in habitat over time, on fish density are taken into account, a significant interaction between reserve status and time is present. This is consistent with the hypothesis that the removal of fishing caused the increase in fish density in the reserve over time.

A visual inspection of the density of $N$. vlamingii against years of reserve protection in Apo reserve (Fig. 2a) suggested evidence of an asymptotic relationship. The best-fitting logistic growth model for this data was $D_{t}=15.88\left(1+e^{-0.28(\mathrm{t}-2.32)}\right)^{-1}$, where $D_{t}=$ density and $t=$ years of reserve protection (Fig. 2b). The bestfitting curve suggests an inflection in the density trajectory between 6 and 9 years of protection, with an asymptote of $15.88 \mathrm{fish} / 1000 \mathrm{~m}^{2}$ being approached after 15-20 years of protection (Fig. 2b).

Outside the reserve, adjacent to the southern boundary, density of $N$. vlamingii increased by a factor of 3.2 close to $(200-300 \mathrm{~m})$, but not further away from (300-500 $\mathrm{m}$ ), the reserve boundary during the first 15 years of reserve protection (Fig. 2c). During the early phase of reserve protection (1983-1987) there was no significant difference in density of $N$. vlamingii with distance from the reserve boundary (Fig. 2c, chi-square $(1 \mathrm{df})=2.76, P>0.05)$. During the two mid-phases of reserve protection (1988-1992 and 1993-1997) there was a significantly higher density of $N$. vlamingii in the area 200-300 $\mathrm{m}$ from the reserve boundary than further away from the boundary (Fig. 2c, chi-square (1 df) $=11.19$ and 11.52, respectively; both $P<0.001$ ). However, this increase in density in the area 200-300 $\mathrm{m}$ from the reserve boundary was not as clear during the next 5 years of reserve protection (1998-2003) (Fig. 2c, chi-square $(1 \mathrm{df})=1.41, P>0.05)$.

Modal size of $N$. vlamingii in the reserve increased from 35 to $45 \mathrm{~cm}$ Total Length (TL) between 1983 and 2003 (Fig. 3), with the 1998-2003 size frequency distribution significantly different from distributions in the reserve at all other times (Kolmogorov-Smirnov (KS) tests, $P<0.05)$. In addition, modal size increased from 35 to $45 \mathrm{~cm}$ TL close to $(200-300 \mathrm{~m})$ but not 


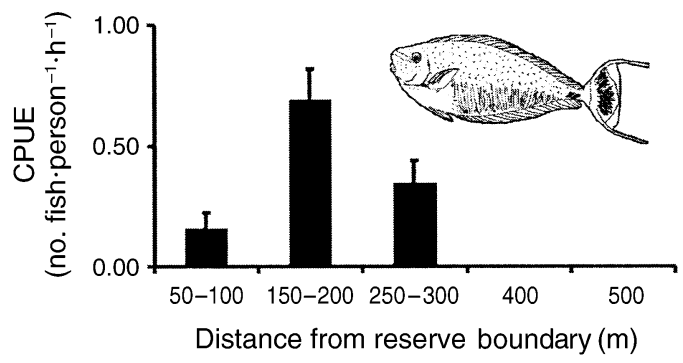

FIG. 4. Results of experimental hook-and-line fishing for Naso vlamingii outside Apo reserve. Catch per unit effort (CPUE; in number of fish per person per hour) at five distances $(50-100,150-200,250-300,400$, and $500 \mathrm{~m})$ from the reserve boundaries. The results for each of the three distances 50-100 m, 150-200 m, and 250-300 m are pooled for the northern and southern boundaries (see Fig. 1). Results for distances $400 \mathrm{~m}$ and $500 \mathrm{~m}$ are from single sites on the southwestern side of the island. Fishing was done above the reef slope between 10 and $20 \mathrm{~m}$. Data are means + SE.

farther from (300-500 m) the reserve boundary over this 20-year period (Fig. 3). At 200-300 m from the reserve boundary, the size frequency distribution in 1998-2003 differed significantly from those in 19881992 and 1993-1997 (KS tests, $P<0.05$ ) (Fig. 3). At 300-500 $\mathrm{m}$ from the reserve boundary, the size frequency distribution in 1983-1987 was significantly different from distributions at all later times (KS tests, $P$ $<0.05$ ), with modal size declining over time (Fig. 3).

\section{Catch rates and size distribution of individuals caught outside the reserve}

Hook-and-line catch per unit effort (CPUE) of Naso vlamingii (in number of fish per person per hour) was highest at 150-200 m outside the boundaries of Apo reserve (Fig. 4). CPUE differed significantly with distance from reserve boundaries $\left(F_{2,84}=7.10, P=0.001\right)$ but not between tides $\left(F_{1,84}=0.51, P=0.48\right)$ nor between the two fished areas (northern and southern) adjacent to reserve boundaries $\left(F_{1,84}=1.15, P=0.29\right)$. There was no significant interaction among distances, tides, and fished areas. CPUE at 150-200 m was significantly higher than at $50-100 \mathrm{~m}$ and $250-300 \mathrm{~m}$ (Tukey's test: $150-200 \mathrm{~m}$ vs. $50-100 \mathrm{~m}, P=0.001$; 150-200 m vs. $250-300 \mathrm{~m}, P=0.05)$ but CPUE at 50-100 $\mathrm{m}$ and $250-300 \mathrm{~m}$ did not differ significantly from each other (Tukey test: $P=0.39$ ). CPUE was zero in the two sites $400 \mathrm{~m}$ and $500 \mathrm{~m}$ from the southern boundary of the reserve (Fig. 4).

$N$. vlamingii that were caught outside the reserve were smaller (mean size: $32.8 \pm 0.5 \mathrm{~cm}$, size range: 25.6 to $38.0 \mathrm{~cm}, n=38$ fish) compared to those recorded in visual censuses (size range: 20 to $54 \mathrm{~cm}$, maximum size recorded inside the reserve only). The mean size of fish captured by hook-and-line was greater closer to (50-100 m) than further away from (250-300 m) the boundaries of Apo reserve (Fig. 5). The fished area adjacent to the northern boundary of the reserve showed a continuous decline of mean size with distance from the reserve (Fig. 5). A two-way ANOVA did not detect significant differences in mean size between the two fished areas $\left(F_{2,32}=2.18, P=0.15\right)$, nor among the three distances from the reserve boundaries $\left(F_{2,32}\right.$ $=3.04, P=0.06)$.

\section{Movement and behavioral interactions among different size classes}

More Naso vlamingii were seen in the reserve than in the fished area adjacent to the northern boundary of the reserve during snorkel observations of movement and behavior of individual fish (reserve: $n=21$ fish, fished area: $n=12$ fish). Individuals that were observed in the reserve during sampling on snorkel were larger on average than in fished areas (reserve, fish size: 32.6 $\pm 2.0 \mathrm{~cm}$ [mean $\pm \mathrm{SE}$ ], range $=19$ to $45 \mathrm{~cm}$; fished area, size $23.4 \pm 2.2 \mathrm{~cm}$, range $=16$ to $38 \mathrm{~cm} ; A N-$ OVA: $\left.F_{1,31}=8.50, P=0.007\right)$. Larger size classes (31-35, 36-40, and 41-45 cm TL) were more common in the reserve than in the fished area (Fig. 6a). No individuals larger than $38-\mathrm{cm}$ TL were seen in the fished area during sampling on snorkel. However no individuals larger than $45-\mathrm{cm}$ TL were seen in the reserve during snorkel sampling (the largest size recorded in the reserve during underwater visual census on scuba was $54-\mathrm{cm}$ TL). This may be due to the limitations of snorkelling. Larger individuals tend to stay on the deeper reef slope $(>12 \mathrm{~m})$ more often $(\mathrm{G} . \mathrm{R}$. Russ, personal observation).

The maximum lateral movement (in one direction) of any individual fish observed on snorkel from a starting point was $40 \mathrm{~m}$. This was recorded for a $16-\mathrm{cm} \mathrm{TL}$ individual during a 15 -min observation period on snorkel in the fished area. The maximum lateral movement of $90 \%$ of observed individuals ranged from 20 to 30 $\mathrm{m}$ from their starting point. Two individuals in the reserve (38- and 41-cm TL) were never observed to move more than $10 \mathrm{~m}$ from their starting point. Maximum lateral movement tended to increase with longer observation time (maximum lateral movement $=0.57 \times$

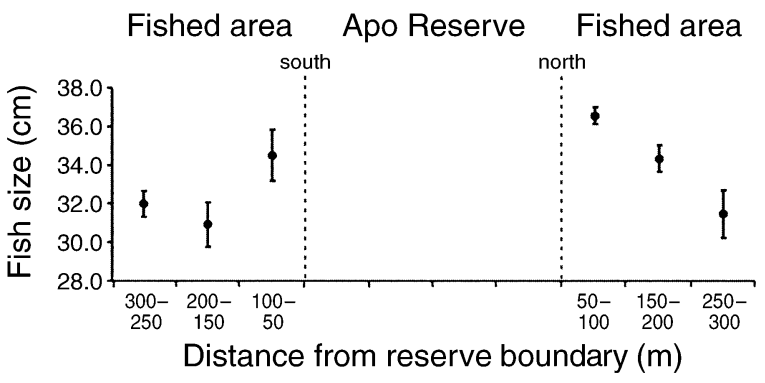

FIG 5. Size (total length, TL, mean $\pm \mathrm{SE}$ ) of Naso vlamingii caught at three distances from the Apo reserve boundaries (north and south). Mean size was highest nearer than farther away from the reserve boundaries. 
Apo Reserve

a) Size

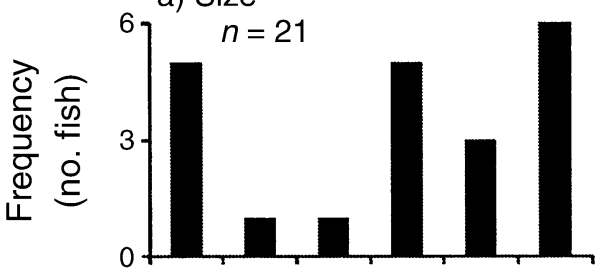

b) Aggression toward smaller conspecifics

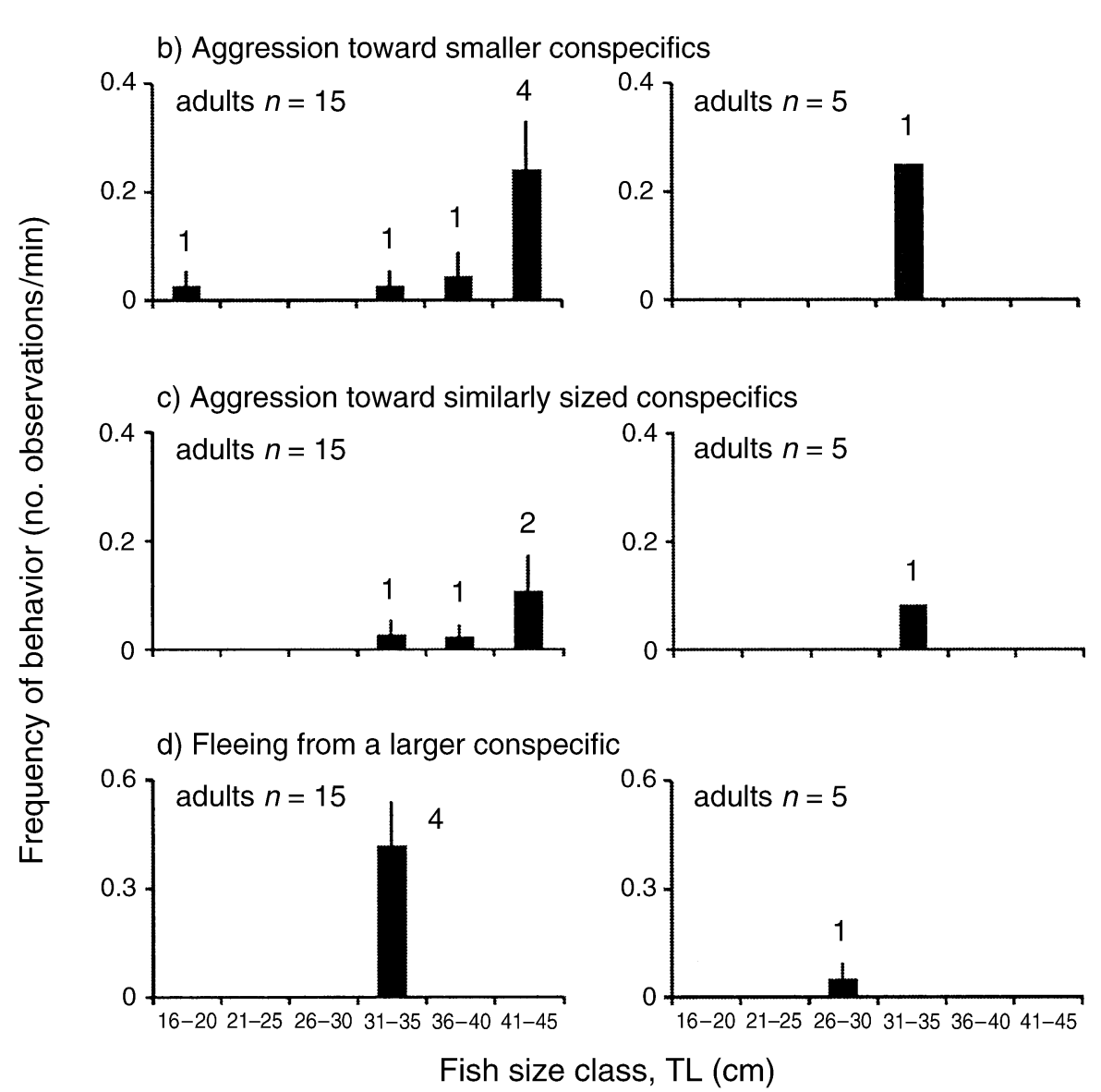

Fish size class, TL $(\mathrm{cm})$
Fished area

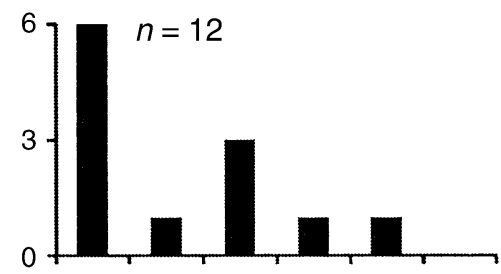

FIG. 6. Results of observations on snorkel of the behavior of Naso vlamingii in Apo reserve and the fished area north of the reserve. (a) Size frequency distribution; (b-d) frequency of sized-based aggression or fleeing. The frequency of a behavior is averaged for each size class, and the number of individuals that displayed that behavior $(n)$ is indicated. Data are means and SE. Juveniles (16-25 cm TL) were not observed to interact with adults $(>26 \mathrm{~cm} \mathrm{TL})$. The number of adults observed is shown for (b), (c), and (d). Observations were done on the reef slope between depths of 5 and $12 \mathrm{~m}$.

[observation time] $+17.58 ; r^{2}=0.16, F_{1,29}=5.41, P$ $=0.03)$. Maximum lateral movement had a tendency to decrease with increasing size of fish (maximum lateral movement $=-0.27 \times[$ size $]+30.80 ; r^{2}=0.16$, $F_{1,29}=5.70, P=0.02$ ).

Movement across reserve boundaries was observed rarely. Only three individuals (9\% of total observations on snorkel) were seen to cross the northern boundary of the reserve. Two of these fish were only $20-\mathrm{cm}$ TL. They were observed first inside the reserve and were seen to move a distance of $\sim 5 \mathrm{~m}$ and $10 \mathrm{~m}$ into the fished area (duration of observation for both individuals: $15 \mathrm{~min}$ ). Only 1 out of 20 individuals $>26-\mathrm{cm}$ TL (5\% of observations) was observed to cross the boundary. This was a $33-\mathrm{cm}$ TL individual that was observed first on the northern boundary and was seen to move $\sim 20 \mathrm{~m}$ into the fished area (duration of observation: $6 \mathrm{~min}$ ). No individuals from the fished area were observed to move into the reserve. No individuals from the reserve were observed to cross the southern boundary of the reserve. 
Aggressive interactions between smaller individuals $<26-\mathrm{cm}$ TL and larger individuals $>26-\mathrm{cm}$ TL were observed rarely. The former are probably juveniles $<5$ yr old (Choat and Robertson 2002). Juveniles were found usually on the shallower reef slope or on the reef flat (3-5 m deep), sometimes in small, loose groups of 3-20 individuals. Some juveniles were observed to graze on algae growing on hard substratum, and feed on plankton. Aggressive interactions among juveniles were rare. Only 1 of 11 juveniles observed displayed aggressive behavior (chasing away a smaller juvenile). Individuals $>26-\mathrm{cm}$ TL are probably adults between 5 and 40 years old (Choat and Robertson 2002). Adults were found usually on the deeper reef slope $(>5 \mathrm{~m}$ deep). Adults were observed to feed on plankton in open water up to $>20 \mathrm{~m}$ away from the reef slope. Aggressive interactions among adults were more common. Of the aggressive interactions among adults observed on snorkel $71 \%$ occurred during feeding.

Aggressive interactions among adults, recorded during snorkel observations of individual fish, were more frequent in the reserve than in the fished area. In the reserve, 6 of 15 adults $(40 \%)$ displayed aggressive behavior towards smaller conspecifics, while 4 of 15 adults (27\%) displayed aggressive behavior towards similarly sized conspecifics. In contrast, in the fished area, only 1 of 5 adults (20\%) displayed aggressive behavior towards smaller or similar-sized conspecifics. In the reserve, aggressive behavior was observed most frequently in adults in the $41-45 \mathrm{~cm}$ size class (Fig. $6 \mathrm{~b}$ and $\mathrm{c}$ ). In the fished area, aggressive behavior was observed on snorkel only in the $31-35 \mathrm{~cm}$ size class (one individual only) (Fig. 6b and c). Aggressive interactions between adults of different sizes always resulted in the larger individual chasing away the smaller one. However, when interacting adults were of similar size, no chasing occurred. Fleeing from a larger conspecific was observed on snorkel more frequently in the reserve than in the fished area. In the reserve, fleeing from a larger conspecific was observed only in the $31-35 \mathrm{~cm}$ size class (4 of 15 adults or 26\%) (Fig. 6d). In the fished area, fleeing from a larger conspecific was observed on snorkel only in the $26-30 \mathrm{~cm}$ size class (1 of 5 adults or $20 \%$ ) (Fig. 6d). No smaller individual was observed to chase away a larger conspecific during snorkel sampling. No larger individual was observed to flee from a smaller conspecific. Observation time on snorkel for adult $N$. vlamingii did not differ significantly between the reserve $(8.4 \pm 1.2 \mathrm{~min}$ [mean \pm $\mathrm{SE}], n=15 \mathrm{fish})$ and the fished area $(7.8 \pm 1.4 \mathrm{~min}$, $n=5$ fish $)\left(F_{1,18}=0.07, P=0.80\right)$.

The mean number of aggressive interactions between $N$. vlamingii observed on scuba on the deeper reef slope was significantly more frequent in the reserve than in the non-reserve areas $\left(t_{38}=3.94, P<0.001\right)$ (Fig. 7). The mean number of aggressive interactions in the reserve was 3.7 times higher than in the non-reserve areas (reserve, $2.83 \pm 0.61$ interactions per replicate [mean

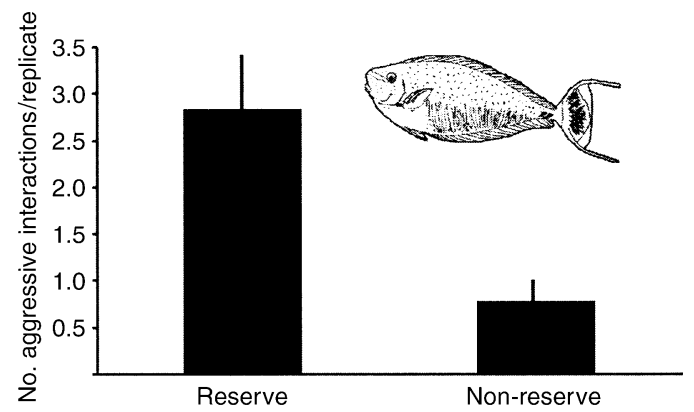

FIG. 7. Number of aggressive interactions per replicate between Naso vlamingii in the Apo reserve and non-reserve areas. Each replicate was a $25 \times 10 \mathrm{~m}$ area of reef slope (at $10-15 \mathrm{~m}$ depth) surveyed for $15 \mathrm{~min}$ using scuba. There were $n=18$ replicates surveyed within the reserve and $n=22$ replicates surveyed outside (both north and south of) the reserve. Data are means; error bars indicate SE.

$\pm \mathrm{SE}$ ] non-reserve, $0.77 \pm 0.24$ interactions per replicate. Aggressive interactions between adults of different sizes almost always resulted in the larger individual chasing away the smaller one.

\section{DISCUSSION}

No study to date of spillover from no-take marine reserves has investigated the potential mechanisms affecting movement of adult fish from reserve to fished areas. Evidence reported here is consistent with a density-dependent mechanism for spillover from Apo reserve (central Philippines). Our present study builds on a previous study of spillover of Naso vlamingii from Apo reserve (Russ et al. 2003). This previous study reported a gradual increase in biomass inside and just outside the reserve, and higher hook-and-line catch per unit effort (CPUE) closer to than further from the reserve boundary. The new lines of evidence in support of spillover, and in support of a mechanism of spillover, in the present paper are the following. Monitoring from 1983 to 2003 documented a three-fold increase in density of N. vlamingii inside Apo reserve (Fig. 2a), and evidence that density had reached an asymptote inside the reserve after 15-20 years of protection (Fig. 2b). The significant interaction between reserve status and duration of protection in the ANCOVA is consistent with the hypothesis that reserve status caused the higher density inside the reserve relative to the non-reserve. Modal size of $N$. vlamingii inside the reserve increased from 35 to $45 \mathrm{~cm}$ TL (total length) over a 20-year period (Fig. 3). This rate of increase in body length is consistent with the known growth rate of the species (Choat and Robertson 2002). Aggressive interactions among adult $N$. vlamingii were 3.7 times more frequent inside than outside the reserve, suggesting that densitydependent interactions were more intense inside the reserve (Fig. 7). Larger individuals almost always chased away smaller ones. However, over short observation periods, adults of $N$. vlamingii were observed to cross the boundaries of the reserve rarely. Outside 
the reserve, density of $N$. vlamingii increased over time close to the reserve boundary $(200-300 \mathrm{~m})$, but not further away (300-500 m) (Fig. 2c). Average size of $N$. vlamingii also increased outside the reserve over the period 1983 to 2003 , but only close to the reserve boundary (200-300 m) (Fig. 3). Hook-and-line CPUE for $N$. vlamingii in 2002 was much higher in the vicinity (50-300 $\mathrm{m}$ ) of the reserve boundaries than elsewhere outside Apo reserve (Fig. 4). Finally, mean size of $N$. vlamingii captured by experimental fishing decreased away from the boundaries of Apo reserve (Fig. 5). Taken together, this represents some of the best evidence available for the development of density-dependent spillover from a no-take marine reserve.

However, the study remains equivocal for a number of reasons. Firstly, we have not been able to demonstrate a gradual increase over time, starting before the reserve existed, in the rates of density-dependent, aggressive interactions of $N$. vlamingii in the reserve location. Secondly, we have not shown a gradual development of directed movements from inside to outside the reserve. Thirdly, we have not demonstrated a change over time in catch rates and average size of $N$. vlamingii caught closer to than further from the reserve.

The increase in both density and modal size of $N$. vlamingii in the reserve from 1983 through 2003 (Figs. $2 \mathrm{a}, 3$ ) implies that some individuals in the reserve could survive to older ages. Since $N$. vlamingii has a long lifespan ( $\sim 40$ years, Choat and Axe 1996), and local people may have fished for the species close to the reserve (Tumoy fishing ground, Fig. 1) for decades, it is likely that a steady increase in abundance inside the reserve would occur only if some individuals that have come to reside in the reserve have some degree of site fidelity. Furthermore, evidence suggests that the density of $N$. vlamingii began to approach an asymptote after 15-20 years of protection (Fig. 2b). This suggests that density of the local population of $N$. vlamingii in the reserve may be reaching an equilibrium, a prediction of density dependence (Hixon and Webster 2002). Two potential mechanisms that could slow the rate of increase of density over time in the reserve are that fish are being excluded from entering the reserve, and/ or are being exported from the reserve, due to the high rates of density-dependent aggressive interactions.

Direct observations of individuals showed that movement of $N$. vlamingii was very limited $(<40 \mathrm{~m}$ radius) in the short term. Also, movement of adults (>26-cm TL) across reserve boundaries was very infrequent. However, these findings were likely due to the short duration of observations ( $\leq 15 \mathrm{~min}$ ). Direct evidence for the emigration of adult fish from a reserve may be obtained from a mark-recapture and/or a tracking study using ultrasonic telemetry. Such studies have been performed at other reserves (Holland et al. 1996, Zeller and Russ 1998, Meyer et al. 2000, Eristhee and Oxenford 2001, Tremain et al. 2004). Such tagging studies were not possible at Apo reserve. The reserve was established by the local community for their own benefit. Manipulative research that requires capturing fish in the no-take area may be counterproductive to the efforts of the local community to maintain protection of the reserve (now protected successfully for 20 years) (Russ et al. 2004).

The very limited movements of larger adults (36-50 $\mathrm{cm}$ TL) from the reserve to fished areas may partially explain why all of the fish caught just outside the reserve during experimental fishing were relatively small (25.6-38.0 cm TL). Alternatively, older (larger) individuals may have learned to avoid baited hooks over time, after escaping from several encounters with them. Anecdotal information from local fishers at Apo Island suggests that larger (older) individuals of $N$. vlamingii are less interested in the baited hooks than smaller (younger) ones (R. Alaton, R. Bantaya, and G. Mendez, personal communication). This information is likely to be accurate, since fishers have to watch the fish take the baited hook to know when to snag it. Local people at Apo Island regard hook-and-line fishing for N. vlamingii as a difficult skill to master (M. Pascobello and G. Mendez, Apo Island residents, personal communication). During experimental fishing, 8 out of 38 individual fish $(21 \%)$ were able to escape, a relatively high percentage. The two fishers in this study were very experienced in this hook-and-line technique. Nonetheless, all of the individual fish that escaped were between $0.6-1.0 \mathrm{~kg}$, or $32-40 \mathrm{~cm}$ TL only (mass estimated by the two fishers, lengths estimated from the mass-length relationship of the catch during experimental fishing). However, larger N. vlamingii can still occasionally be caught outside Apo reserve using bamboo traps. A very large catch (about 200 individuals) of both large $(>1.0$ $\mathrm{kg})$ and small $(<1.0 \mathrm{~kg}) N$. vlamingii was reported in just two bamboo traps on the Tumoy fishing ground in October 2002 (L. Autor, R. Autor, and A. Dameles, fishers at Apo Island, personal communication) (Fig. 1 ). This one incident, removing a very large number of fish from the area about $200 \mathrm{~m}$ from the southern boundary of the reserve (Fig.1), could have contributed substantially to the distinct decline in abundance of $N$. vlamingii within 200-300 m of the reserve boundary from 1993-1997 to 1998-2003 (Fig. 2c).

Results of this study are more consistent with a longer term, density-dependent mechanism for spillover, rather than with occasional spillover. A compelling result from experimental fishing was the trend of decreasing mean size of $N$. vlamingii away from the boundaries of Apo reserve (Fig. 5). Mean size decreased from 34.5 to $32.0 \mathrm{~cm}$ TL away from the southern boundary, and from 36.6 to $31.5 \mathrm{~cm}$ TL away from the northern boundary. N. vlamingii caught by experimental fishing outside the reserve were relatively small adults $(25.6-38.0 \mathrm{~cm}$ TL). The pattern of decreasing mean size away from the reserve boundaries suggests that these smaller adults may have relocated their home ranges from inside to just outside the re- 
serve over time. Density-dependent spillover is hypothesised to produce a gradient of higher to lower mean size from inside to outside a reserve (Rakitin and Kramer 1996, Kramer and Chapman 1999), rather than an abrupt decline in mean size as one moves from inside to outside the reserve boundary. An alternative explanation for our results would be that larger fish are absent outside the reserve due to fishing mortality removing larger fish. However, this would be unlikely to cause a gradient of decreasing size of fish caught as one moves away from the reserve, as seen in this study (Fig. 5).

Competition for space, food, or mates among adult $N$. vlamingii inside the reserve is a probable mechanism that could explain the pattern of decreasing mean size of fish caught as one moves away from the boundaries of Apo reserve. Furthermore, a size hierarchy appears to be involved in this competition. Larger adults may eventually drive out the smaller adults from the reserve. Individuals of $N$. vlamingii seem to become more territorial (display aggressive behavior and some degree of site attachment) as they grow larger and older (Fig. $6)$. Also, more of the larger adults were found inside the reserve (Figs. 3 and 6). Aggressive interactions on a per fish basis were 3.7 times more frequent in the reserve (Fig. 7). Furthermore, when interacting adults differed significantly in size, the larger individual almost invariably chased away the smaller one.

A less compelling result is the pattern of catch per unit effort for $N$. vlamingii at different distances from the reserve boundary (Fig. 4). The significant peak in CPUE at 150-200 $\mathrm{m}$ from the reserve boundaries (compared to 50-100 $\mathrm{m}$ and 250-300 $\mathrm{m}$ from the boundary) appears inconsistent with that expected from spillover. However, the peak at 150-200 m from each boundary appears to correspond to the location of good habitat for feeding of $N$. vlamingi, such as steep drop-offs. In the absence of data on spatial patterns of CPUE over time, we cannot conclude with confidence that spillover contributed to the present spatial pattern. However, what is clear is that similar good habitat at greater distances from the reserve does not appear to have higher CPUE of N. vlamingii (Fig. 4, Russ et al. 2003). It is also clear that CPUE for $N$. vlamingii was much higher in the vicinity $(50-300 \mathrm{~m})$ of the reserve boundaries than elsewhere outside Apo reserve (Fig. 4).

Evidence for density-dependent movement of fish has been reviewed recently by Jennings (2001) and Rose et al. (2001). Jennings (2001) provides several examples of the ranges occupied by fish populations changing in response to density. For example, at low stock abundance the northern anchovy, Engraulis mordax, occurs in high densities in areas of most suitable habitat, but occupies a wider range of habitats at lower density when stock abundance increases (MacCall 1990). Cod (Gadus morhua) are believed to have moved back into preferred habitats as population size was reduced by fishing, thus maintaining high density at these preferred sites (Hutchings 1996). Butl et al. (1999) showed that selection of different habitats by juvenile Atlantic salmon, Salmo salar, in experimental river enclosures, depended on density in those habitats. Evidence for density-dependent movement of coralreef fishes is largely unknown (Jones and McCormick 2002). However, evidence for home-range relocation in reef fishes is increasing (Robertson 1988, Lewis 1997). The only attempt to study the effect of density on movement patterns of coral-reef fishes experimentally was made by Zeller et al. (2003). They reduced the density of large predators adjacent to two no-take reserves by $57-83 \%$ to increase the density gradients across the reserve boundaries. However, a significant change in the frequency and direction of movement by tagged large predators was not detected after manipulation. Zeller et al. (2003) suggested that the lack of a "response" after manipulation may have been due to insufficient density in the marine reserve to cause resource limitation.

The greater frequency of competitive interactions inside than outside the reserve, the size hierarchy in competitive interactions, and the declining mean size of fish as one moves away from the boundary of the reserve, imply that it is the intermediate-sized fish, not the largest (or smallest) fish that are most likely to spillover. Such a density-dependent mechanism of spillover is obviously not consistent with the suggestion that reserves will export the largest fish. The occasional capture of very large fish (Roberts et al. 2001) or lobsters (Kelly et al. 2002) from areas adjacent to no-take reserves, sizes much larger than those caught from more distant fishing grounds, is not consistent with such a mechanism of spillover. The gradual development over time of the frequency of capture of record-sized fish close to the Merritt Island no-take reserve in Florida (Roberts et al. 2001), may have been due to the occasional emigration of a large fish independent of any density-dependent mechanism. Alternatively, fish that were exported from Merritt Island may have survived fishing long enough outside the reserve to attain record size before capture. The fact that the modal size of $N$. vlaming $i$ was the same inside and just outside (200-300 m) the Apo reserve in the period 1998-2003 (Fig. 3), after 15-20 years of effective reserve protection, suggests that at least some fish driven out of the reserve by size-based competition survived fishing and grew outside that reserve.

The size hierarchy in competitive interactions among adults in the present study also implies a relationship between potential spillover from the reserve and recruitment of juveniles into the reserve. $N$. vlamingii probably exhibits an ontogenetic movement from the shallower to the deeper reef slope. Juveniles were found usually on the reef flat or the shallow reef slope, while adults were found mainly on the deeper reef slope. This suggests that juveniles that recruit into the reserve will probably move to the same habitat as adults 
as they grow older. However, individuals that have grown recently into young adults will be smaller than many of the older adults because the latter may survive to larger sizes in the reserve due to protection from fishing. Furthermore, some of the older adults may defend their home ranges in the reserve for several years, even for decades, because of their long lifespan (Choat and Axe 1996). Hence, the smaller (younger) adults that may eventually be driven out of the reserve by larger (older) adults could be members of a cohort of juveniles that recruited to the reserve reef flat several years earlier. Thus, the occurrence and magnitude of spillover events driven by competition inside the reserve may also depend on the frequency and strength of earlier successful recruitment events. Density-dependent spillover may wax and wane in strength in the long term, driven by recruitment pulses.

In conclusion, the results of this study are consistent with one mechanism of spillover from a no-take reserve-long-term development of density dependence. Competition for space, food, or mates may result in emigration of smaller adult fish from the reserve. However, the evidence for this remains equivocal. Our present study did not show that competition inside the reserve intensified over time, nor that the distribution of smaller adult fish outside the reserve changed over time. However, it still represents some of the best evidence available for density-dependent spillover from a no-take marine reserve.

\section{ACKNOWLEDGMENTS}

Some financial support for this research was provided by the United Nations Environment Program and the Natural Resources Management Center of the Philippines (1983), the Great Barrier Reef Marine Park Authority (1985), and a Pew Fellowship (1999-2003) to G. R. Russ and A.C. Alcala. R. A. Abesamis was also supported by an Australian Development Scholarship from the Australian Agency for International Development (AusAID). We wish to thank A.C. Alcala for his continued inspiration and support. Thanks to Brian Stockwell for assistance in collection of fish interaction data in November 2004. Thanks also to all of the staff at the Silliman University Angelo King Center for Research and Environmental Management and the Marine Laboratory, Silliman University, Dumaguete City, Philippines. Thanks also to the people of Apo Island, especially G. Mendez and R. Alaton for assistance with experimental fishing.

\section{Literature Cited}

Armsworth, P. R. 2002. Recruitment limitation, population regulation, and larval connectivity in reef fish metapopulations. Ecology 83:1092-1104.

Bellwood, D. R. 1988. Seasonal changes in the size and composition of the fish yield from the reef around Apo Island, central Philippines, with notes on methods of yield estimation. Journal of Fish Biology 32:881-893.

Butl, T. P., S. C. Riley, R. L. Haedrich, R. J. Gibson, and J. Heggenes. 1999. Density-dependent habitat selection by juvenile Atlantic salmon (Salmo salar) in experimental riverine habitats. Canadian Journal of Fisheries and Aquatic Sciences 56:1298-1306.

Choat, J. H., and L. M. Axe. 1996. Growth and longevity in acanthurid fishes; an analysis of otolith increments. Marine Ecology Progress Series 134:15-26.
Choat, J. H., and D. R. Robertson. 2002. Age-based studies. Pages 57-80 in P. F. Sale, editor. Coral reef fishes, dynamics and diversity in a complex ecosystem. Academic Press, San Diego, California, USA.

Cocheret de la Moriniere, E., B. J. A. Pollux, I. Nagelkerken, and G. van der Velde. 2002. Post-settlement life cycle migration patterns and habitat preference of coral reef fish that use seagrass and mangrove habitats as nurseries. Estuarine and Coastal Shelf Science 55:309-321.

Côté, I. M., I. Mosquera, and J. D. Reynolds. 2001. Effects of marine reserve characteristics on the protection of fish populations: a meta-analysis. Journal of Fish Biology 59(Supplement A):178-189.

Dahlgren, C. P., and D. B. Eggleston. 2000. Ecological processes underlying ontogenetic habitat shifts in a coral reef fish. Ecology 81:2227-2240.

Dayton, P. K., E. Sala, M. J. Tegner, and S. F. Thrush. 2000 Marine protected areas: parks, baselines, and fishery enhancement. Bulletin of Marine Science 66:617-634.

Eristhee, N., and H. A. Oxenford. 2001. Home range size and use of space by Bermuda chub Kyphosus sectatrix (L.) in two marine reserves in the Soufriere Marine Management Area, St. Lucia, West Indies. Journal of Fish Biology 59:129-151.

Gell, F. R., and C. M. Roberts. 2002. The fishery effects of marine reserves and fishery closures. World Wildlife FundUS, Washington D.C., USA.

Gell, F. R., and C. M. Roberts. 2003. Benefits beyond boundaries: the fishery effects of marine reserves. Trends in Ecology and Evolution 18:448-455.

Halpern, B. S. 2003. The impact of marine reserves: Do reserves work and does size matter? Ecological Applications 13:S117-S137.

Hilborn, R., et al. 2004. When can marine reserves improve fisheries management? Ocean and Coastal Management 47: 197-205.

Hixon, M. A., and M. S. Webster. 2002. Density-dependence in reef fish populations. Pages 303-325 in P. F. Sale, editor. Coral reef fishes, dynamics and diversity in a complex ecosystem. Academic Press, San Diego, California, USA.

Holland, K. N., C. G. Lowe, and B. M. Wetherbee. 1996. Movements and dispersal patterns of blue trevally (Caranx melampygus) in a fisheries conservation zone. Fisheries Research 25:279-292.

Hutchings, J. A. 1996. Spatial and temporal variation in the density of northern cod and a review of hypotheses for the stock's collapse. Canadian Journal of Fisheries and Aquatic Sciences 53:943-962.

Jackson, J. B. C., et al. 2001. Historical overfishing and the recent collapse of coastal ecosystems. Science 293:629638.

Jennings, S. 2001. Patterns and prediction of population recovery in marine reserves. Reviews in Fish Biology and Fisheries 10:209-231.

Jones, G. P., and M. I. McCormick. 2002. Numerical and energetic processes in the ecology of coral reef fishes. Pages 221-238 in P. F. Sale, editor. Coral reef fishes, dynamics and diversity in a complex ecosystem. Academic Press, San Diego, California, USA.

Kaufman, K. W. 1981. Fitting and using growth curves. Oecologia 49:293-299.

Kaunda-Arara, B., and G. A. Rose. 2004. Effects of marine reef National Parks on fishery CPUE in coastal Kenya. Biological Conservation 118:1-13.

Kelly, S., D. Scott, and A. B. MacDiarmid. 2002. The value of a spillover fishery for spiny lobsters around a marine reserve in northern New Zealand. Coastal Management 30: 153-166.

Kramer, D. L., and M. R. Chapman. 1999. Implications of fish home range size and relocation for marine reserve function. Environmental Biology of Fishes 55:65-79. 
Lewis, A. R. 1997. Recruitment and post-recruit immigration affect the local population size of coral reef fishes. Coral Reefs 16:139-149.

Lieske, E., and R. Myers. 1997. Reef fishes of the world. Periplus Editions, Hong Kong China.

MacCall, A. D. 1990. Dynamic geography of marine fish populations. University of Washington Press, Seattle, Washington, USA.

McClanahan, T. R., and B. Kaunda-Arara. 1996. Fishery recovery in a coral-reef marine park and its effect on the adjacent fishery. Conservation Biology 10:1187-1199.

McClanahan, T. R., and S. Mangi. 2000. Spillover of exploitable fishes from a marine park and its effect on the adjacent fishery. Ecological Applications 10:1792-1805.

Meyer, C. G., K. N. Holland, B. M. Wetherbee, and C. G. Lowe. 2000. Movement patterns, habitat utilization, home range size and site fidelity of whitesaddle goatfish, Parupeneus porphyreus, in a marine reserve. Environmental $\mathrm{Bi}$ ology of Fishes 59:235-242.

Morgan, I. E., and D. L. Kramer. 2005. Determinants of social organization in a coral reef fish, the blue tang, Acanthurus coeruleus. Environmental Biology of Fishes 72:443-453.

Mumby, P. J., and C. C. C. Wabnitz. 2002. Spatial patterns of aggression, territory size, and harem size in five sympatric Caribbean parrotfish species. Environmental Biology of Fishes 63:265-279.

Nagelkerken, I., and G. van der Velde. 2002. Do non-estuarine mangroves harbour higher densities of juvenile fish than adjacent shallow-water and coral reef habitats in $\mathrm{Cu}-$ racao (Netherlands Antilles)? Marine Ecology Progress Series 245:191-204.

NRC [National Research Council]. 2001. Marine protected areas: tools for sustaining ocean ecosystems. National Academy Press, Washington, D.C., USA.

Pauly, D., V. Christensen, S. Guénette, T. Pitcher, U. R. Sumaila, C. Walters, R. Watson, and D. Zeller. 2002. Towards sustainability in world fisheries. Nature 418:689-695.

Rakitin, A., and D. L. Kramer. 1996. Effect of a marine reserve on the distribution of coral reef fishes in Barbados. Marine Ecology Progress Series 131:97-113.

Roberts, C. M., J. A. Bohnsack, F. Gell, J. P. Hawkins, and R. Goodridge. 2001. Effects of marine reserves on adjacent fisheries. Science 294:1920-1923.

Roberts, C. M., and N. V. C. Polunin. 1991. Are marine reserves effective in management of reef fisheries? Reviews in Fish Biology and Fisheries 1:65-91.

Robertson, D. R. 1988. Abundances of surgeonfishes on patch-reefs in Caribbean Panama: Due to settlement, or post-settlement events? Marine Biology 97:495-501.

Robertson, D. R. 1998. Implications of body size for interspecific interactions and assemblage organization among coral-reef fishes. Australian Journal of Ecology 23:252257.

Robertson, D. R., and S. D. Gaines. 1986. Interference competition structures habitat use in a local assemblage of coral reef surgeonfishes. Ecology 67:1372-1383.

Rose, K. A., J. H. Cowan, K. O. Winemuller, R. A. Myers, and R. Hilborn. 2001. Compensatory density-dependence in fish populations: controversy, understanding and prognosis. Fish and Fisheries 2:293-327.

Russ, G. R. 2002. Yet another review of marine reserves as reef fishery management tools. Pages $421-443$ in P. F. Sale, editor. Coral reef fishes, dynamics and diversity in a complex ecosystem. Academic Press, San Diego, California, USA.
Russ, G. R., and A. C. Alcala. 1996. Do marine reserves export adult fish biomass? Evidence from Apo Island, Central Philippines. Marine Ecology Progress Series 132:1-9.

Russ, G. R., and A. C. Alcala. 1999. Management histories of Sumilon and Apo Marine Reserves, Philippines, and their influence on national marine resource policy. Coral Reefs 18:307-319.

Russ, G. R., and A. C. Alcala. 2004. Marine reserves: longterm protection is required for full recovery of predatory fish populations. Oecologia 138:622-627.

Russ, G. R., A. C. Alcala, and A. P. Maypa. 2003. Spillover from marine reserves: the case of Naso vlamingii at Apo Island, the Philippines. Marine Ecology Progress Series 264: $15-20$

Russ, G. R., A. C. Alcala, A. P. Maypa, H. P. Calumpong, and A. T. White. 2004. Marine reserve benefits local fisheries. Ecological Applications 14:597-606.

Russ, G. R., B. Stockwell, and A. C. Alcala. 2005. Inferring versus measuring rates of recovery in no-take marine reserves. Marine Ecology Progress Series 292:1-12.

Sale, P. F. 1978. Reef fishes and other vertebrates: a comparison of social structures. Pages 313-346 in E. S. Reese and F. J. Lighter, editors. Contrasts in behavior. John Wiley and Sons, New York, New York, USA.

Sale, P. F., R. K. Cowen, B. S. Danilowicz, G. P. Jones, J. P. Kritzer, K. C. Lindeman, S. Planes, N. V. C. Polunin, G. R. Russ, Y. J. Sadovy, and R. S. Steneck. 2005. Critical science gaps impede use of no-take fishery reserves. Trends in Ecology and Evolution 20:74-80.

Sanchez Lizaso, J. L., R. Goni, O. Renones, J. A. Garcia Charton, R. Galzin, J. T. Bayle, P. Sanchez Jerez, A. Perez Ruzafa, and A. A. Ramos. 2000. Density dependence in marine protected populations: a review. Environmental Conservation 27:144-158

Shulman, M. J. 1985. Coral reef fish assemblages: intra- and interspecific competition for shelter sites. Environmental Biology of Fishes 13:81-92.

Sobel, J. A., and C. P. Dahlgren. 2004. Marine reserves. A guide to science, design and use. Island Press, Washington D.C., USA.

Sutherland, W. J., J. A. Gill, and K. Norris. 2002. Densitydependent dispersal in animals: concepts, evidence, mechanisms and consequences. Pages 135-151 in J. M. Bullock, R. E. Kenward, and R. S. Hails, editors. Dispersal ecology. Blackwell Publishing, Malden, Massachusetts, USA.

Tremain, D. M., C. W. Harnden, and D. H. Adams. 2004. Multidirectional movements of sportfish species between an estuarine no-take zone and surrounding waters of the Indian River Lagoon, Florida. [U.S. National Marine Fisheries Service] Fishery Bulletin 102:533-544.

Willis, T. J., R. B. Millar, R. C. Babcock, and N. Tolimieri. 2003. Burdens of evidence and the benefits of marine reserves: Putting Descartes before des horse? Environmental Conservation 30:97-103.

Willis, T. J., D. M. Parsons, and R. C. Babcock. 2001. Evidence for long-term site fidelity of snapper (Pagrus auratus) within a marine reserve. New Zealand Journal of Marine and Freshwater Research 35:581-590.

Zeller, D. C., and G. R. Russ. 1998. Marine reserves: patterns of adult movement of the coral trout (Plectropomus leopardus (Serranidae)). Canadian Journal of Fisheries and Aquatic Sciences 55:917-924.

Zeller, D. C., S. L. Stoute, and G. R. Russ. 2003. Movement of reef fishes across marine reserve boundaries: effects of manipulating a density gradient. Marine Ecology Progress Series 254:269-280. 